\title{
The house survey trap: The state of mind needed to undertake an instruction successfully
}

Received (in revised form): 7 th October, 2005

\begin{abstract}
Roy Ilott FRICS
is a Chartered Building Surveyor and member of the Expert Witness Institute, and started his building surveying practice in 1980 after 14 years' experience in maintenance and alterations to many types of buildings. He thus had a wide experience base for carrying out many structural surveys to houses and small commercial properties, which he only stopped recently as the Expert Witness instructions on negligence and building disputes increased. He speaks for the RICS on television, radio and to the press on housing and building defect issues.
\end{abstract}

\begin{abstract}
The surveyor entering a house to carry out a building inspection should be equipped with more than a high level of technical knowledge and the latest relevant gadgets, they also need to enter with a high degree of awareness and good communication skills. Just as the animal prowling the jungle needs to have all its senses alert and the soldier entering the battle zone needs to have more than just the latest technology, the surveyor must be aware of the pitfalls likely to be encountered. The most dangerous trap is that which is unexpected. With surveyors the biggest risk may be the communication of their findings and conclusions. Many books and articles have been written on techniques and equipment for carrying out the successful house inspection. This paper considers the attitude, or even state of mind, necessary for the safe and profitable expedition through this particular jungle.
\end{abstract}

\section{Keywords:}

disputes, negligence, surveys, defects, competence, claims, damages

Roy llott \& Associates Nightingale House 46-48 East Street Epsom KT17 $1 \mathrm{HQ}$, UK Tel: +44 (o) 1372727926 Fax: +44 (0) 1372745498 E-mail: info@royilottsurveyors.co.uk

\section{INTRODUCTION}

Surveyors need to review the 'what' and the 'why' of their instruction, and to consider the 'who' of their instruction. The what, why and who should always be front of mind, not only when surveyors are inspecting, but especially when they are drafting their report. Is the prospective purchaser buying for their own occupation or to rent? Are they planning extensive alterations and refurbishment works? Do they expect to move in and do no work? Do they have the knowledge, skill and resources to tackle extensive works, even if on a DIY basis? Are they buying at the full stretch of their resources? Perhaps most important of all, are there particular fears or bad experiences which they are bringing from previous houses? While it is not possible to ask these questions, they are the areas where the surveyor should be alert to information being passed by the prospective purchaser, their client, when taking the instruction and 


\section{Remember the purchaser is not emotionally detached}

\section{Confirm and be clear}

\author{
Do not try and impress \\ with technical terms - \\ keep it clear, keep it \\ simple
}

confirming what is required. This is one particular area where the sole practitioner has an advantage over a surveyor from a larger office who may not be able to talk to their client.

The report is the link between surveyors and their clients, between a surveyor's experience and their client's expectation, between a surveyor's past experiences and perhaps their client's future liabilities, between the client's solicitors and a professional indemnity insurance claim.

At this point, it is worth reminding surveyors to ensure their instructions are clear to all, and that everything is confirmed in writing. If the building is not as anticipated from the telephone enquiry, and the three-bedroom detached house turns out to be three bedrooms, plus box rooms, changing rooms, bathrooms, numerous reception rooms etc, surveyors should not try to fit the survey to the quoted price. It is much safer and more professional to call back and renegotiate the price. If the description was deliberately misleading, the client will not be happy with the report in any case, probably will not pay and potentially will be liable to sue to pay for some of their repairs.

It is important when approaching the building that surveyors do not make assumptions as to their client's existing knowledge or skill base. Assumptions, even made subconsciously, may affect a surveyor's notes and subsequently the tone with which the defects, the downside or even assets of the building are reported. Thus surveyors should not make assumptions as to the resources and ability of the client to cope with, for example, the inevitable redecoration which, as an experienced surveyor, one considers is absolutely essential and so obvious that it almost does not need to be stated.

While surveyors may be aware of the Building Research Establishment's classification of cracks (BRE, 1995), most purchasers consider that the definition 'serious' applies long before a gap of $25 \mathrm{~mm}$ occurs. The surveyor who is not aware of this attitude is running the risk of not communicating his expertise and decisions in the most appropriate form.

At this point, it is worth reminding the reader that negligence is not the same as being wrong. Negligence is not showing the level of care and skill which are reasonably to be expected from a competent surveyor working in that position. Being wrong is usually considered to be more a case of drawing an incorrect assumption from evidence which was available on site and was clearly considered. There are extensive case histories available for those who wish to develop and follow the differences and these definitions further.

\section{ROUTINE RULES ... OK!}

On many occasions, in similar papers and at talks, surveyors will have been advised to have a system or procedure for carrying out an inspection and, the author believes, after many years' experience, this is essential. The inspection can be carried out either on an element-by-element basis or a room-by-room basis. Sometimes it is necessary to modify the format between, for example, houses and warehouses. It may be beneficial to walk around a house to obtain a general feel of the building without 
You can never have too many notes if the survey becomes a complaint making any specific notes, followed by a second walk around, inspecting and commenting on the structure and main elements. A third tour covers the fittings, elements and decorations in each of the rooms and areas. While the notes for the first two tours are usually linked on an elemental basis, those for the last visit are on a room-by-room basis and this is thus when services and fittings are listed and comments made on their condition. The author usually finishes with the roof space. The exterior is inspected after the first walk round and perhaps the roof is re-inspected after a trip into the loft. Drains are inspected last, after the loft, so that all the dirty work is completed at the end of the inspection.

It is very prudent, particularly when tackling any unusual or complicated buildings or during one's initial years, that a simple tick-list is available to make sure that all of the elements have been included. This is often particularly useful for items which seem to move everywhere; for example, the cold water storage tank is sometimes located within the roof space, in other houses it is above the hot water cylinder in the airing cupboard and in some properties there is no tank at all because it has a pressure-fed system.

As far as the actual survey is concerned, it is crucial that surveyors keep clear records and notes of the evidence available as, should a dispute evolve, another surveyor (who by questioning one's report may not appear to be the expert one would have selected) will be viewing notes two or three years later and asking for the reason why illegible notes led to the conclusion that they did. If the matter is not resolved, the cross-examination in court will be even more harrowing.

Similarly, no matter how persuasive the client may be, surveyors should not rush the survey or do it in different sections purely because the vendor wishes to control the pace of the survey or inspection. After all, surveyors are the people carrying the liability and it is their expertise, opinion and advice that are crucial to the whole operation.

If the surveyor's standard routine gets interrupted, for example, when access is provided to a locked room, then they should make sure to record it in the site notes to return to the missed areas, as under the pressure of a long inspection this easily can be omitted. Tact is needed to persuade the talkative vendor or inquisitive child to leave one in peace, especially as the surveyor will still want the vendor to impart information, but only when asked.

Similarly, it is very important to note what one did see, even if no defects were recorded in that particular room. Indeed, there can be disputes with surveyors where the claimant has alleged that if the surveyor had inspected a particular room he would have seen the cracks - because there is no note to say that he did, it is assumed that he did not inspect it. Similarly, if access is restricted internally and there are indicators externally of a potential problem, this fact should be recorded, not only in the site notes, but also in the final survey report. For example, if there is a pile of logs leaning against an external, solid, nine-inch-thick brick wall and on the inside face the wall is covered with timber kitchen units, logically there could be problems in the wall and any buried fixing battens which are totally obscured. Thus photographs which record the layout and 
state of a room can be of great benefit, particularly if they are recording the amount of furniture and stored possessions which clearly restrict access for the survey.

The survey is almost a battle of will and wits between surveyors and the subject property. It is a detective exercise to find out the good and bad points, the assets and liabilities of the building. It is a contest to find out the history of defects and repairs, and to see if there are any signs or indicators of future faults or failings. Once the building has been diagnosed, then the first part of the survey is completed.

It is a regrettable part of surveyors' skill and responsibility that they need to prepare for a potential claim while carrying out the survey in the first place. Thus it is essential that clear and adequate notes are prepared which should be legible to a third party. Unfortunately, the majority of surveyors spend many hours walking around buildings and over the years the scribbling notes slowly become a shorthand which is only decipherable to the writer. The other option of dictating notes, unfortunately, is even less satisfactory as there are then no written notes made at the time of the inspection to be made available to substantiate the surveyor's claim that he acted with due diligence, that he recorded all of the facts that were visible on site and that he did visit the particular area in question.

\section{CLARITY IS CRUCIAL}

The report is the second part of the instruction and perhaps it is the most complicated. As indicated earlier, it is necessary to assess how surveyors communicate the results of their detective work in a clear, meaningful and unambiguous way to a client who has probably already obtained a positive and thus prejudiced view of the property, and thus probably has a tendency to ignore any blatant negative statements. If they did not like or want the building, they would not have made an offer and started writing cheques to solicitors and others. Surveyors' success in accurately communicating their assessment of the building is the measure of the client's satisfaction, now and when they take occupation.

On many occasions the author has encountered surveyors who have written a report as if they were addressing a colleague in the office, or an equally technically aware and emotionally detached individual. It is essential to realise that, in the majority of cases, the prospective purchaser of this 'highly desirable property' has short-listed this particular building as the place they want to call home. They have not just viewed some walls and a roof, they have seen it as the place where their dreams can be realised, the place to which they can retreat at the end of a hard day, home where they can bring up a family, or the location where they can carve their own character. To forget this is to risk being misunderstood. Thus everything which is said in the report must be suitably worded, not just being a list of negatives, but drawing attention to the true nature of the building within a clear and balanced framework. If the client subsequently discovers that their dream has become a nightmare of defects, disasters and costs, the reverse side of their enthusiasm will become, or may develop into, a driving force which will pursue their claim against the 
surveyor for what they may perceive to be his negligence in not dragging them away from their dream before they invested a vast fortune that has tied them down for the rest of their working life to a disappointing and frustrating wreck. In the client's eyes this purchase is unlikely to be their fault, and in the current culture of litigation and 'rights' not 'responsibilities', their misplaced optimism will be replaced by the surveyor's gross negligence.

If, for example, surveyors are considering the wording for a survey of an older building with solid brick walls, the limitations to their inspection can be set out in several ways, or in different statements:

'We have not been able to report on any rot or other defects which may or may not exist in buried timbers.'

This is likely to be dismissed as a 'typical surveyor's cop-out' and will not be considered. If, however, one considers an alternative paragraph:

\begin{abstract}
'Buildings of this period are frequently found to contain timbers built into the wall as fixing points for finishes, such as dado rails, or fixing points for fittings. As these are covered by plaster, but remain vulnerable to damp from interstitial condensation and penetrating rainwater, we cannot confirm if they have begun to decay. However, there are no visible indications on the face of the walls that such decay or deterioration exists in the accessible external walls.'
\end{abstract}

The second option is more likely to be considered and remain in the client's mind should rotten timbers be discovered during subsequent alterations. The same approach and text can be adopted, without a wordfor-word repetition, for such items as wall plates or joist ends.

When setting out reasons for a statement, surveyors should make sure that these are clearly stated. The italics highlight three very simple words, but each has a crucial meaning.

- Reasons: The reason is the basis on which an experienced surveyor, using reasonable skills, has come to a decision on the condition of a particular element or feature.

- Clearly: These decisions and the conclusion must be stated in a clear and unambiguous fashion, which even the most optimistic prospective purchaser, viewing the world through very rose-tinted spectacles, will not misunderstand.

- Stated: It is also important that all reasons are developed in a logical fashion so that the conclusion and considered advice cannot be misunderstood. It is not a surveyor's job to make the decisions. It is their job to provide the information against which the prospective purchaser makes those decisions. If the reasons are clearly stated then any possible claim for negligence should fall down at the first legal analysis.

What to include... that is the question
Surveyors should not volunteer information which they cannot substantiate. Thus if the age of the building is unknown, why guess? If a surveyor does not know the depth of the foundations, the report should not describe them, or even indicate what they 'are likely to be'. What matters is whether they appear, at the point when the survey was carried out, to be 
adequate. Similarly, the report should not state what the sub-soil is. Even a trial pit only gives information on the soil at that spot, and the geological survey gives a general indication. So unless one has some very specific information, or can explain the limits of the information, advice should not be volunteered or statements made in the report which may be wrong.

There is a difference of opinion as to whether a summary should be included at the end of the report, but it is worth considering that by selecting half a dozen points to list at the end of the report, the surveyor encourages the client not to read the whole document and to make a decision not based on its entirety.

Another area of debate is in respect of providing costs of the reported repairs. The author has always suggested that prospective purchasers obtain estimates from 'their preferred contractor' for the reported repairs. This is because surveyors cannot influence the nature or size of contractors which the client wishes to use, and the cost difference between the VAT-free, one-man band and the full supported and structured firm of craftsmen is substantial. While useful, some of the standard price books need skill to interpret the cost preparation for small jobs, but they can provide an industry recognised starting point.

Surveyors will never prevent claims being made, but if the surveyor is well prepared then it should be possible to counter these at an early stage. Surveyors are also subject to claims which are due to the errors of others, thus a client once requested compensation because a side extension roof had leaked between the survey and occupation dates. He claimed that the survey had not referred to the flat roof over the side extension and the defects which existed there. Discussion revealed that this element 'had not been underlined' in the text of the report. On being asked to explain, it transpired that their solicitor had been sent the report before they read it, he had underlined the stated defects and they had only read these highlighted sections. Neither had registered the statement that the flat roof over the side extension could not be inspected and was probably at the end of its life, but if instructed the surveyor would revisit with a builder and long ladder. The claim was dropped.

These comments may appear to be very negative, but surveyors need to be prepared for spurious claims to be made against them even years after the inspection. The expert acting on the surveyor's behalf can only provide an opinion and draw conclusions based on the information provided by the surveyor. To be of great benefit to the client and to cover the surveyor against future claims, this information must be supported by photographs, documents, notes etc.

\section{THE FUTURE}

The impending Home Inspector Reports will raise new areas of interest. It has been held in the past that surveyors owe a duty of care to all those reasonably relying on their advice. Thus the mortgagee has been owed a duty of care following a mortgage valuation and report carried out on behalf of the mortgagor. The new Home Inspector Reports will extend this further. They are also likely to have a stated or accepted shelf life.

A survey is a view of the building, its condition and defects, only at the 
time of the survey and the surveyor cannot be responsible for defects which occur even the day after the inspection. This obviously does not apply where the 'damage' follows from a defect or symptom that is visible. The unexpected leak and resultant ceiling collapse, the subsidence crack which can develop over a few days, or services failure, cannot realistically be the surveyor's liability. Others will disagree, but if the new reports are to be valid for a period, possibly three months, it will be interesting to see how this liability is phrased or covered by insurers.

\section{Reference}

BRE (1995) BRE Digest 251, BRE, Watford, UK 